\title{
EDUCAÇÃO DE JOVENS E ADULTOS: PERCURSOS E CONFLITOS
}

\author{
YOUTH AND ADULT EDUCATION: COURSES AND CONFLICTS
}

Antonio Carlos dos Santos Cruz ${ }^{1}$

Universidad Autónoma de Asunción

\begin{abstract}
Resumo
O presente artigo teve como objetivo geral demonstrar, no âmbito da EJA, os resultados de entrevistas realizadas diretamente com os atores sociais, no município de Vila Velha - ES, analisando suas perspectivas. A importância de se discutir acerca dos caminhos pedagógicos a serem percorridos com vistas a sanar as problemáticas encontradas é o que justifica a realização deste trabalho, tanto social, como academicamente. Considerando-se o caráter explicativo da pesquisa, depreende-se que a abordagem metodológica utilizada é qualitativa. Constatou-se que os professores valorizam profundamente sua relação com os estudantes, sentindo-se exemplos para eles. Dentre as dificuldades apontadas, sobressaiu a questão do multisseriamento. Concluiuse, como ponto mais relevante das informações coletadas, a perspectiva adotada pela grande maioria dos professores da EJA, da importância dos alunos da EJA estarem preparados profissionalmente, preparados para o mercado de trabalho. Essa é uma postura que coaduna completamente com a consolidação do pensamento elitista e dualista.
\end{abstract}

Palavras-chave: Aprender; Educação; Jovens e Adultos.

\section{Abstract}

The objective of this article was to demonstrate, within the scope of the EJA, the results of interviews conducted directly with the social actors, in the city of Vila Velha - ES, analyzing their perspectives. The importance of discussing the pedagogical paths to be followed in order to solve the problems encountered is what justifies the accomplishment of this work, both socially and academically. Considering the explanatory character of the research, it can be deduced that the methodological approach used is qualitative. It was found that teachers deeply value their relationship with students, feeling themselves as examples for them. Among the difficulties pointed out, the question of multisession class stood out. It was concluded as the most important point of the collected information, the perspective adopted by the vast majority of adult education teachers, the importance

\footnotetext{
${ }^{1}$ Graduado em Tecnologia em Metalurgia e Materiais pelo Instituto Federal de Educação, Ciência e Tecnologia do Espírito Santo, IFES (2006). Cursou Licenciatura em Química até o $5^{\circ}$ período, trancando o curso, posteriormente. Especialista em Língua Portuguesa pela Faculdade de Nova Venécia (2009). Especialista em Matemática pelas Faculdades Integradas de Jacarepaguá (2010). Mestrado em Ciências da Educação na Universidad Del Norte (2012). Doutorado em Ciências da Educação na Universidad Autónoma de Asunción (2019).
} 
of adult education students be prepared professionally, prepared for the labor market. This is a posture that completely conforms to the consolidation of elitist and dualistic thinking.

Keywords: Learning; Education; Young people and Adult.

\section{INTRODUÇÃO}

Educação Infantil, Ensino Fundamental e Ensino Médio são as etapas da educação brasileira, enquanto a Educação de Jovens e Adultos - EJA - constitui uma modalidade que visa ao atendimento de pessoas que não cursaram as etapas em seu momento mais adequado. A EJA continua sendo um legado vivo da história dualista da educação nacional, e os sujeitos que frequentam essa modalidade precisam ser mais bem compreendidos e respeitados pelos educadores, posto que, antes de qualquer coisa, requerem um direito que sempre Ihes pertenceu, mas Ihes foi tirado. Ao analisar as diferentes situações que levaram esses indivíduos a permanecerem fora da escola, encontram-se sempre causas de origem socioeconômicas, bem como a ineficiência do Estado em propiciar uma rede de ensino pública eficaz, capaz de manter as crianças na escola, com um ensino de qualidade em todo o território nacional.

Ademais, na EJA, o ato de avaliar é essencial e precisa considerar as particularidades do público atendido: um público adulto. Há de ser ter em mente, além dos problemas próprios relacionados à modalidade, como as dificuldades que os alunos enfrentam em conciliar responsabilidades de trabalho e família com o estudo, ou os conteúdos a serem ministrados, a relação professor/aluno e as dificuldades enfrentadas na atuação docente, o fato de que tais pessoas podem ser desprovidas de conhecimentos escolares, mas são sujeitos pensantes, sujeitos que sabem quando não estão sendo tratados com respeito, sujeitos capazes de perceber quando o professor não está interessado em, verdadeiramente, ensinar-Ihes, e usa do processo avaliativo como mera quantificação de notas.

Mas isso não significa que o professor deva ser sentenciado como único culpado e responsável pelo fracasso e abandono da escola. O tema de discussão aqui proposto deriva-se da pesquisa empreendida durante uma tese de doutorado, que investigou, na EJA do município de Vila Velha, localizado no estado do Espírito Santo, alguns dos fatores acima mencionados.

Para que o direito à educação seja assegurado aos alunos da EJA, e para que essa educação adquira um caráter emancipador, como defende Paulo Freire (2008), é preciso 
entender a realidade desse alunado enquanto "seres para o outro", pessoas dotadas de história e cultura, seres que, muito embora não possuam conhecimentos acadêmicos e escolares, constituem-se sujeitos ativos da própria história, e a educação deve servir como um instrumento em prol da emancipação e libertação desses sujeitos.

É por entender a importância da educação para a emancipação dos indivíduos da EJA que esse estudo se debruçou sobre o questionamento: Qual é a perspectiva dos professores com relação ao procedimento avaliativo, aos conteúdos ministrados, à relação professor/aluno e às dificuldades encontradas em sua atuação, dentro das instituições que oferecem a EJA no município de Vila Velha - ES?

A importância de se discutir e apontar possíveis caminhos pedagógicos a serem percorridos com vistas a sanar as problemáticas encontradas - pois se entende que muito além de evidenciar os problemas existentes, é preciso pensar, refletir e propor soluções é o que justifica a realização deste trabalho, tanto social, como academicamente.

A qualidade da educação pública ofertada no Brasil há muito vem sendo discutida. Buscam-se as causas para o fracasso escolar, para os altos índices de reprovação e para os baixos resultados apresentados pelos estudantes brasileiros em todas as disciplinas do currículo escolar, em todas as etapas da educação básica. Além disso, é um fato que a avaliação tem sido vista por um longo tempo como um processo quantificador de resultados, cuja principal finalidade seria medir o desempenho dos alunos por meio de testes, provas e trabalhos, os quais muitas vezes servem apenas como instrumentos perpetuadores da reprodução irreflexiva do conhecimento.

Nesse contexto, o objetivo geral deste artigo é demonstrar, no âmbito da EJA, os resultados das entrevistas realizadas diretamente com os atores sociais que compuseram a amostra, analisando suas perspectivas. Para que a discussão seja profícua, entende-se que há necessidade de perpassar alguns objetivos específicos, a saber: 1. Sintetizar a evolução da EJA no Brasil, confrontando problemas e suas causas; 2. Realizar apontamentos acerca dos processos avaliativos, dos conteúdos ministrados para esse público, da relação professor/aluno e as dificuldades que se perpetuam no âmbito escolar; 3. Discutir as respostas dadas pelos professores em função dos apontamentos teóricos.

Ressalta-se que este trabalho não tem a intenção de exaurir o tema tratado, mas fomentar uma discussão no escopo da academia e da sociedade, na busca por uma sociedade equânime. 


\section{EJA - PERCURSOS E CONFLITOS}

É preciso compreender as razões da necessidade de haver além das etapas da educação básica uma modalidade destinada à EJA. Primeiramente, há demanda. Em outras palavras, existem milhares de pessoas pelo Brasil, que não puderam frequentar o espaço escolar na idade adequada, ou tiveram que abandonar os estudos muito cedo, pessoas que se encontram em situação de analfabetismo ou semianalfabetismo.

É para essas pessoas que a EJA se destina. Assim, parece lógico e coerente que a primeira análise que deve ser feita é justamente aquela que aponta os motivos pelos quais existem tantos indivíduos adultos analfabetos, cerceados desde a infância em seu direito básico à educação e que agora precisam buscar pelos conhecimentos escolares ao mesmo tempo em que tentam conciliar essa realidade com suas vidas repletas de responsabilidades de adultos.

A realidade é que nenhuma das questões relativas à EJA pode ser completamente entendida sem uma revisão da evolução histórica da educação no Brasil, pois é imprescindível considerar os aspectos políticos, econômicos e sociais, os quais se acham intimamente ligados aos processos educativos.

A história da educação brasileira inicia-se com a vinda dos jesuítas ao Brasil colonial, os primeiros a organizar escolas e ministrar aulas, em razão da necessidade de instruir a população local nas primeiras letras, para que fosse catequizada (SAVIANI, 2008). A EJA germinou já neste período, quando os padres jesuítas começaram a catequizar as populações adultas da então colônia brasileira (ALMEIDA; CORSO, 2015).

Posteriormente, as reformas Pombalinas que expulsaram os jesuítas e instauraram um modelo educacional dirigido pelo Estado, e mesmo as modificações trazidas pela vinda da família real portuguesa ao Brasil, mantiveram uma dualidade vigente e constante na educação, com um ensino erudito e científico restrito, especialmente em termos financeiros, somente aos nobres, aristocratas e burgueses, e um ensino popular, com objetivos ligados à qualificação progressiva da mão-de-obra necessária para a manutenção da economia em funcionamento (SAVIANI, 2008).

Assim, as origens se encontram na própria história da educação brasileira, da qual a EJA é inseparável. O Brasil, país que iniciou seu processo histórico como colônia de Portugal, em seus poucos mais de 500 anos foi marcado por uma sucessão de governos preocupados em atender as demandas da elite nacional, deixando a classe popular sempre em segundo plano, como ensina o professor Anísio Teixeira (1994). 
Sempre coexistiram dois sistemas distintos de educação, um direcionado a educar a elite nos conhecimentos eruditos e científicos que Ihes eram necessários para perpetuar-se no poder, e um segundo sistema destinado a prover a classe popular da instrução, necessário para que pudesse ocupar os postos de trabalho e, assim, servir aos interesses econômicos do Estado, um sistema dual de ensino que serviu primeiro a um país de senhores e escravos, e depois de senhores e povo.

Com a proclamação da república, o sistema educacional brasileiro não apresentou melhoras significativas. Os primeiros anos republicanos se dedicaram a consolidar o novo sistema de governo no país e pouco se preocupou com a qualidade do ensino ofertado (SAVIANI, 2008).

Mesmo posteriormente, nas intensas campanhas de alfabetização promovidas durante o período da Segunda Guerra Mundial e nos inúmeros outros programas e estratégias governamentais direcionadas à EJA, elaborados durante as décadas seguintes, sempre se manteve um caráter voltado para a qualificação do aluno, a fim de que adquirisse competências para adentrar no mercado profissional (BESERRA; BARRETO, 2014).

A EJA foi especialmente empregada, durante todos os períodos educacionais brasileiros, para essa finalidade. Nesse sentido, "a Educação de Jovens e Adultos tem uma trajetória histórica de ações descontínuas, marcada por uma diversidade de programas, muitas vezes não caracterizada como escolarização" (ALMEIDA; CORSO, 2015, p. 1284). Segundo Cook-Gumpertz (1991, p. 40):

As demandas de escolarização e de alfabetização foram crescendo não tanto por pressão da classe trabalhadora, mas sim por necessidade de mantê-la sob controle da classe dominante. O objetivo maior da escolarização era controlar a alfabetização, e não promovê-la; controlar tanto as formas de expressão quanto ao comportamento que acompanham a passagem em direção à alfabetização. $O$ desenvolvimento da escolarização pública passou a basear-se na necessidade de atingir-se uma nova forma de treinamento social, para transformar os trabalhadores domésticos ou rurais em força de trabalho operário.

Ainda, conforme Teixeira (1994), a partir da metade do século XX iniciaram-se tentativas de fundir os dois polos, fazendo com que as escolas públicas ministrassem um conhecimento mais elaborado, destinado a atender a demandas sociais de forma mais ampla. Não obstante, a dicotomia entre elite e povo permaneceu, e ainda permanece. Neste contexto, é importante mencionar que Freire efetuou uma verdadeira ruptura na história pedagógica do país e da América Latina. Através da criação da concepção de educação popular, consolidou um dos paradigmas mais ricos da pedagogia contemporânea, rompendo radicalmente com a educação elitista e comprometendo-se verdadeiramente 
com homens e mulheres. Freire (2008, p. 20) entende que "toda prática educativa tem como objetivo ir além de onde se está". O método envolvia localizar e recrutar os analfabetos de determinada área ou comunidade, e convidá-los à alfabetização. Prosseguia mediante entrevistas com os adultos inscritos nos círculos de cultura e outros habitantes selecionados entre os mais antigos e os mais conhecedores da realidade (FREITAS, 2003).

Portanto, o sistema de ensino público brasileiro nunca foi neutro, e, por mais que os governantes tenham afirmado primar pela educação como um direito de todos, é necessário adquirir a capacidade crítica de ver além desse discurso e enxergar que por trás de cada fase da história da educação brasileira diversos interesses políticos e econômicos prevaleceram. Como bem afirma Freire (1996, p. 56) a respeito da qualidade política da educação, "é impossível, na verdade, a neutralidade da educação. E é impossível, não porque professoras e professores "baderneiros e subversivos" o determinem. A educação não vira política por causa da decisão deste ou daquele educador. Ela é política".

É com este enfoque que este artigo foi pensado, guiando-se pela Pedagogia Libertadora construída por Paulo Freire, a qual se pauta primordialmente pela busca da emancipação histórica dos sujeitos através de seu processo educativo, e, igualmente, guiando-se pelas palavras sabiamente pronunciadas por Teixeira (1994), de que a educação não é privilégio, e a escola tem uma missão na qual não pode falhar: formar o caráter e a inteligência.

Partindo do que foi pressuposto por esses dois grandes nomes da História da Educação no Brasil, Freire (1996) e Teixeira (1994), é necessário que, no escopo da academia, sejam incentivadas as discussões em torno de como é, atualmente, concretizada a EJA nos rincões do país. Tratar a EJA nos maiores centros urbanos é relevante, assim como qualquer tema que busque a evolução do sistema educacional brasileiro. Entretanto, deve-se ter em mente que há muitos municípios no território nacional nos quais a assistência é ínfima, e, para além de se pensar os problemas estruturais da EJA, a observação e investigação junto aos atores sociais envolvidos se torna significativa.

Nesse contexto, dentro dos problemas estruturais, encontra-se o procedimento avaliativo. A avaliação é um processo capaz de servir a bem mais que para a mensuração do conhecimento. No entender do estudo aqui apresentado, ela é uma importante ferramenta de ensino. Quando utilizada com critérios bem definidos e com objetivos educacionais claros, o ato de avaliar se torna uma forma de ensinar, e o conhecimento adquirido tanto serve para apontar para o aluno os aspectos que precisa melhorar, quanto 
para delinear para o professor resultados reais que atestam a eficácia (ou não) de suas metodologias de ensino.

Todo o processo de ensino/aprendizagem pode ser revisto e melhorado a partir dos resultados de uma avaliação bem empreendida. Como explica Luckesi (2002, p.17):

A característica que de imediato se evidencia na nossa prática educativa é de que a avaliação da aprendizagem ganhou um espaço tão amplo nos processos de ensino que nossa prática educativa escolar passou a ser direcionada por uma pedagogia do exame.

Diante de tudo que foi exposto, é necessário entender: "por meio da educação escolar, os indivíduos têm, diante de si, um "mundo" do qual até então não tinham consciência" (LAFFIN, 2011, p. 86). Certamente, conheciam-no a seu modo e não da maneira como a ciência sistematizou suas experiências ao longo dos anos. Isso significa dizer que a educação escolar fomenta o conhecimento de cada sujeito, levando a se descobrir e descobrir outras coisas que sequer tinha consciência, mas que, em muitas situações, já estavam ali latentes.

Essas pessoas de origem humilde, em sua maioria exercendo trabalhos braçais durante o dia todo e se dispondo, mesmo sob intenso cansaço, a estudar no período noturno, guardam histórias de vida ricas em cultura e experiências, e, mesmo que lhes faltem os conhecimentos escolares, podem não carecer de percepção e sabedoria diante da vida, pois, como explica Laffin (2011, p. 180):

A condição do sujeito adulto está marcada pela história, cultura, sua constituição familiar e inserção ou não no mundo do trabalho. Condições essas, que de certa forma, também se traduzem, assim como no jovem, na sua realidade e localiza as suas diferentes situações de classe, etnia, raça, gênero, nível de escolaridade.

Convém questionar, antes de adentrar a análise dos resultados, quem são os alunos da EJA? Quais histórias carregam? Quais suas aspirações e sonhos? O alunado da EJA é composto por homens e mulheres de diferentes idades, mas que possuem em comum o fato de não terem conseguido concluir seus estudos e precisarem retornar aos bancos escolares, conforme já foi apontado. Portanto, são pessoas adultas, com responsabilidades de adulto, como trabalho e família, mas que partem em busca de concluir seus estudos, e muitos o fazem para conseguir uma melhor colocação no mercado de trabalho.

Todos os contextos aqui abordados são fundamentais para a criação de uma nova mentalidade em torno da EJA, e para a discussão de novas possibilidades. É inegável a necessidade da consolidação de políticas públicas que amparem educadores e educandos, que, devido à sua condição de vida, já se encontram em uma situação de fragilidade social. Nesse sentido, desde a colonização do Brasil, como foi visto, a EJA se insere no escopo 
da economia nacional e da política, refletindo socialmente a estratificação de classes, que se perpetua com o passar dos anos, um problema que merece ser ampla e profundamente discutido no país.

\section{MÉTODO}

Este trabalho se constituiu a partir de um estudo de caso, relatando e analisando diretamente a experiência vivenciada por professores e estudantes da EJA no município de Vila Velha. Considerando-se o caráter explicativo da pesquisa, que busca, para além do entendimento de um fenômeno sociocultural, apontar fatores capazes de contribuir para sua ocorrência, depreende-se que a abordagem metodológica utilizada é caracterizada como qualitativa. Nesse sentido, ressalta-se que "a abordagem qualitativa se centra na identificação das características de situações, eventos e organizações" (LLEWELLYN; NORTHCOTT, 2007, apud FREITAS; JABBOUR, 2011, p. 9).

O estudo do qual se derivou o presente artigo foi realizado durante o ano de 2018. Ao todo, em Vila Velha, 21 escolas oferecem a EJA. Os resultados que aqui se apresentam são referentes à pesquisa realizada na Região $\mathrm{V}$, desenvolvida em cinco escolas, dentre as quais, UMEF Alger Ribeiro, localizada na Cidade da Barra; UMEF Gov. Christiano Dias Lopes, localizada em São Conrado; UMEF Aylton de Almeida e UMEF Profo Paulo Cesar Vinha, ambas localizadas em Terra Vermelha; UMEF Profo ${ }^{\circ}$ Darcy Ribeiro, localizada na Morada da Barra. Foram entrevistados 50 professores e 200 alunos da EJA, ouvidos presencialmente e individualmente entre os meses de junho e novembro. O presente artigo expõe as perspectivas dos professores, acerca das questões que foram anteriormente apontadas, o que compõe a amostra.

\section{RESULTADOS}

A legislação regulamentadora da EJA em Vila Velha é o Regimento Comum das Escolas Municipais de Vila Velha, aprovado pelo Conselho Municipal de Educação em 2008. A Grade Curricular do ensino noturno é tratada como Ensino Fundamental Regular Semestral Noturno, conforme Lei no. 3112/95 de 13/01/95, Resolução CME n002/03 de 07/07/2003.

Os conteúdos, por sua vez, são distribuídos em: Português, Matemática, História, Geografia, Ciências, Língua Estrangeira e Artes. As atividades de Ed. Física são oferecidas através do Projeto "Barra Um Lugar ao Sol", no turno Matutino, de forma opcional. São apresentados os Indicadores Fixos: $n^{\circ}$ de dias letivos, 100; nº de dias semanais, 05; $n^{\circ}$ de 
semanas letivas, 20; duração do recreio, 15 minutos; período aula, 50 minutos; Início das aulas, 18h20; Término das aulas, 22h00; horário de planejamento, 18h00 às 18h40. Esse é o panorama organizacional da EJA na cidade de Vila Velha (VILA VELHA, 2013). A autonomia escolar se dá a partir do trabalho em conjunto de pedagogos e professores.

É preciso ressaltar que todas as escolas pesquisadas possuem uma boa estrutura física, contam com bons materiais didáticos, livros de literatura e pesquisa, espaço bem iluminado e ventilado, além de cardápio elaborado por nutricionistas. Acerca do alunado da EJA, a questão alimentícia é fundamental, pois todos os estudantes trabalham, muitos em funções que envolvem intenso esforço físico; assim, as escolas oferecem o jantar e não apenas um lanche.

Observou-se que as salas de aula das EJA possuem alunos de diferentes séries. Para orientar-se no trabalho desenvolvido junto a cada turma distinta, os professores utilizam as cores dos livros didáticos. Os alunos são orientados pelos professores separadamente na hora em que desenvolvem cada atividade, o que exige que um mesmo docente efetue diversos planejamentos, destinados a atender as distintas séries, e os tenha de aplicar simultaneamente, já que as séries convivem na mesma sala de aula, em um esquema de multisseriamento.

Ademais, em todas as escolas analisadas, tanto em sua organização, quanto em seus Projetos Políticos Pedagógicos, incluindo especialmente os objetivos direcionados para a EJA, percebe-se que todas são muito semelhantes, o que demonstra a existência de uma uniformização de suas bases, e no próprio projeto estrutural que define o espaço destinado à EJA.

Além disso, o processo avaliativo é empreendido em todas as escolas pesquisadas, através de questionários respondidos pelo professor e de seus relatórios de observação. Tais observações são relatadas diretamente aos alunos, ou para os pais, em encontros individuais que ocorrem semestralmente.

A pesquisa realizada sobre a EJA em Vila Velha constatou que existem tanto pontos positivos nos processos de ensino aprendizagem quanto aspectos que precisam ser melhorados. Quando questionados sobre os processos avaliativos na EJA, os professores mencionaram a utilização de exercícios, participação e avaliação processual diária, demonstrando terem uma nítida preocupação com a identificação das dificuldades dos educandos e correção/reformulação dos rumos didático-pedagógicos seguidos. Nas palavras dos entrevistados: 
PROFESSOR 13: Na sala de aula é feito muito exercício, a gente, eu particularmente, procuro não passar atividades para casa, por que a maioria trabalha, né? E não vai ter tempo de fazer! Então, as avaliações são todas feitas em sala de aula, acompanhamento, e eu procuro sempre fazer várias atividades para que eles componham a nota. Não há prova com valor alto.

\section{PROFESSOR 37: Participação!}

PROFESSOR 25: A avaliação é feita diariamente, e depois, no final do semestre, mas todo dia eles são avaliados como um todo. O aluno não é só avaliado nas classes de alfabetização dessa primeira parte de Ensino Fundamental, eles são avaliados como um todo. Todo dia tem uma produção de texto. A participação, a confecção de cartazes, de trabalhos que são feitos dentro da sala, por que para o aluno da EJA, você não pode dar dever de casa, vamos dizer assim!

Preocupam-se igualmente em adaptar os conteúdos ministrados em sala à realidade dos educandos da EJA, mencionando, especificamente, que a forma de trabalhar com esse alunado não pode ser a mesma como se trabalha com as crianças das primeiras séries do Fundamental, embora os conteúdos ensinados sejam os mesmos. Conforme os docentes:

PROFESSOR 42: Nesse semestre, a gente está trabalhando em cima do tema de profissões. É por conta da proximidade deles... desses alunos já estarem perto do mercado de trabalho. Então, a gente, na informática, a gente procura unir, né, já todas as ferramentas da informática com esse tema de profissões, pra eles fazerem teste vocacional e pesquisarem sobre a profissão, saberem o que eles vão ser, né? Em que eles pretendem se formar? E aí, a gente, além disso, já encaminha para o mercado com uma formação de computação, que é essencial pra qualquer profissão hoje em dia.

PROFESSOR 31: Pois é! A EJA tem o currículo específico, que vem direto da prefeitura. A gente trabalha dentro do que eles mandam, e geralmente tudo que vem é dentro do cotidiano de cada aluno, com os recursos que eles podem utilizar, ou materiais que eles podem conseguir em casa, tudo dentro da ótica deles.

PROFESSOR 20: É! Essa preocupação nossa é muito grande. O conteúdo não pode ser um mesmo conteúdo que é dado durante o dia para os alunos de $1^{\underline{a}}$ a $4^{\underline{a}}$ séries, né? Por que, nesse caso, seria $1^{\circ}$ ao $5^{\circ}$ ano. À noite ainda é série, é seriado. São conteúdos que nós estudamos junto com a direção da escola, com corpo pedagógico, equipe pedagógica, para escolher o que melhor convém em relação aos alunos, né? Pra quê que ele vai usar isso na vida dele profissional? Hoje, por exemplo, estamos trabalhando com recibo, né? Como ele dá um recibo? Como ele recebe? Preenchimento de cheque, textos que condizem com a realidade do aluno. Não pode ser um texto muito infantil. Tudo de acordo com a idade e com faixa etária dele.

Ademais, os docentes demonstraram compreender a importância da manutenção de uma relação harmoniosa entre professor e aluno, respeitando, primordialmente, o ser humano que ali se encontra, e reconhecendo-o como um ser dotado de cultura e sabedoria. Nas palavras de alguns docentes entrevistados:

PROFESSOR 23: Olha... eu acho que é fundamental, né? Tem que ser uma relação bem junta, né? Como eu disse, pra que o aluno sinta confiança, por que tem muita coisa do aluno do EJA, que não sente confiança, às vezes, no professor, pelo fato dele, às vezes, na rua... ele ter sofrido algum tipo de preconceito, de abuso, ou alguma coisa. E aí eles sentem, muitas das vezes... uma retração pelo professor. 
PROFESSOR 11: Cara, até o final. Por que os alunos têm a gente como o exemplo, né? Então, a gente procura é ser sempre pontual, sempre junto com eles... qualquer dúvida, eles têm a gente para tirar... qualquer horário, qualquer momento... Eu acho que o tempo inteiro a gente necessita.

PROFESSOR 9: Eu acho que o relacionamento é muito importante. Confiança que eles têm que ter no professor, têm que gostar desse professor, porque se não, fica uma barreira, né?

Mas, a EJA também apresenta suas dificuldades para a atuação docente, como afirmam os seguintes participantes:

PROFESSOR 4: Então... É em cima dessa resposta anterior. É essa dificuldade dos alunos! Deles já virem, eles já terem estudado num ensino normal, e após alguma dificuldade, né... de trabalho... ou de família, né, eles voltarem pra escola na EJA. Então, às vezes, você pega alunos que estão há 5,10 anos sem entrar numa escola. Essa é umas das principais dificuldades.

PROFESSOR 46: Ah, cara! Pra mim é quando um aluno não é uma pessoa que trabalha. Por exemplo: uma pessoa que já ficou retida em vários outros anos, não tem disciplina, ou por que é uma "criança" meio rebelde, ou por que tem déficit de atenção. Quando é um trabalhador que vem em busca do tempo perdido, aí é vapo-vapo.

PROFESSOR 28: No meu caso, a dificuldade maior é por que estão $1^{\underline{a}}, 2^{\underline{a}}, 3^{\underline{a}}$ e $4^{\underline{a}}$, todos numa série, e às vezes eu me sinto incapaz. Sempre eu acho que deixo um pouco a desejar numa turma. Outro dia, em outra turma. É por que, como nós falamos: estão todos juntos e misturados. Mas é bom, que um ajuda o outro. A nossa turma é muito participativa, graças a Deus.

\section{DISCUSSÃO}

Percebeu-se, no discurso dos professores sobre as práticas avaliativas, concepções conflitantes, que vislumbram uma tendência às mudanças. O professor 13 , por exemplo, declara uma preocupação com a "composição da nota" e aplicação de provas, ainda que com valor baixo, ao passo que o professor 37 avalia por meio da participação dos alunos, e o professor 25 avalia por meio das atividades realizadas em sala.

Ainda assim, foi possível constatar a preocupação com o respeito e com os conhecimentos prévios dos estudantes durante o planejamento da avaliação. Isso significa que "aos poucos, a ideia de avaliar como prática para medir resultados vem sendo abandonada, em prol de outra ideia que a considera como prática de análise do processo e identificação de obstáculos à aprendizagem" (BRASIL, 2006, p. 108).

Nesse sentido, recorde-se o que afirmou Luckesi (2002), apontando a pedagogia do exame, que sempre teve espaço na educação brasileira mais marcadamente na postura do professor 13, enquanto a perspectiva do afastamento do procedimento técnico e a observação das necessidades dos educandos, abordados por Pelloso (2014), na voz dos professores 37 e 25. 
O que se depreende dentre a multiplicada de declarações dos professores é que há uma maioria que adota uma metodologia avaliativa mais flexível, mas, ainda assim, existe entre alguns professores uma concepção da soberania da prova e da nota no processo de aprendizagem, como como norteadora para o estudante e para si mesmo, nem como incentivo à evolução, mas como cumprimento de normas institucionais, de certa forma, irrevogáveis.

Entre os professores entrevistados em Vila Velha, foi possível perceber que há preocupação em torno da adaptação dos conteúdos ministrados, envolvendo a realidade dos estudantes, como declararam as três amostras aqui apontadas. Ainda assim, é importante ressaltar que, como relata o professor 31, os conteúdos são direcionados pela prefeitura da cidade, que envia os materiais didáticos.

Se os materiais estão voltados para a realidade do aluno, e se orientam ao preenchimento de recibos, de cheques, como confirmou o professor 20, e, mais que isso, se eciste uma preocupação tão intensa, como afirmou o professor 42 de realizem exames vocacionais e deixem a escola com conhecimentos de informática, "essencial pra qualquer profissão hoje em dia", esses materiais didáticos e essa postura adotada pelas políticas públicas estão pensando na formação integral do alunado, na construção de sujeitos críticos e conscientes, como declarou Freire (1996)? Essa educação oferecida tem caminhado na direção de um rompimento com a educação elitista, como era a proposta de Freire (1996), e tem se desvinculado da dicotomia elite e povo, apontada por Teixeira (1994).

Também os professores, em seus discursos, não têm inculcada a ideia da educação voltada para estritamente a formação profissional desses sujeitos, fomentando a ideia de que a escola serve apenas para dar aos alunos algum suporte na carreira profissional que seguirem? Embora a educação libertadora de Paulo Freire seja a base da formação dos professores no Brasil, o que, realmente se absorve de sua teoria, ou o que, realmente, se constrói dentro das escolas?

Por outro lado, também inserida na perspectiva da educação libertadora, e dos novos moldes que têm transformado a educação no mundo inteiro, os relatos indicam que há uma grande preocupação dos professores acerca da interação com o alunado. Parece incontestável essa percepção que os professores possuem em torno da necessidade que o estudante possui em confiar no docente, estabelecer vínculos com ele, para que a aprendizagem seja mais eficaz. Foi possível confirmar que para os educadores é de extrema importância tornar a aprendizagem mais significativa para todos, com propostas 
alternativas que estejam comprometidas com uma educação de qualidade para esses jovens e adultos, como afirmam necessário Gadotti e Romão (2011).

Os professores demonstram entendimento de que é preciso ter um olhar diferenciado para esses alunos, buscando despertar neles o gosto pelo o estudo através das interações e mediações professor/aluno. Este ponto é um dos mais relevantes a serem ressaltados, pois somente em uma relação respeitosa é possível estabelecer um processo de ensino aprendizagem mais efetivo, assim como somente em tal contexto pode o professor conhecer, verdadeiramente, o universo vivenciado pelo aluno e, assim, manter um processo avaliativo coerente e uma metodologia de ensino apropriada.

Dentre as dificuldades apontadas pelos professores, algumas questões tornam-se evidentes e sobressaíram, como o fato das salas de aulas serem compostas por turmas mistas das quatro primeiras séries do Fundamental, o que sem dúvida constitui uma dificuldade para o exercício pleno da função docente. Recorde-se que essa dificuldade também foi apontada por Porcaro (2011, p. 50), quem constatou como problema da EJA "a heterogeneidade de níveis de aprendizagem dentro de cada turma, na qual o educador da EJA tem de atender, ao mesmo tempo, educandos que se encontram no início do processo de alfabetização e educandos que se encontram no final do processo".

Sendo assim, esse parece ser um problema existente nas mais variadas regiões do país, sem que se manifeste nenhuma intenção de mudança por parte das políticas públicas. $E$, além disso, contando com o fato de que em Vila Velha as turmas da EJA também contam com alunos com necessidades especiais, percebe-se que há uma grande diversidade nas salas de aula dessa etapa, são muitos contextos que implicam na necessidade de uma metodologia específica e de uma formação apta a preparar o docente para atuar na EJA.

Ademais, considerou-se relevante que as turmas da EJA não compostas apenas por trabalhadores, mas também por alunos repetentes, que por possuírem dificuldades de aprendizagem ou até mesmo problemas de disciplina acabaram ficando atrasados em suas turmas, e, ao adquirir a idade mínima necessária, buscam pela EJA. Nesse sentido, acabase partindo para outros problemas da educação brasileira, envolvendo especialmente Ensino Fundamental, que, como não são foco do presente trabalho, não carece que sejam mais amplamente discutidos.

A título de enriquecimento das informações aqui prestadas, ainda que expondo de forma generalizada, considerou-se relevante acrescentar que, na concepção dos alunos da EJA no município de Vila Velha, as principais dificuldades encontradas estão no grande barulho em sala de aula, a conversa paralela dos colegas, que atrapalha o entendimento, 
e, concernente ao trabalho diário da professora em sala de aula, também questionam as dificuldades que os professores têm para atender aos alunos em um contexto de multisseriamento.

A dificuldade em ser aluno de uma sala de aula na qual convivem diferentes séries também é sentida pelos próprios estudantes, assim como os problemas relativos a indisciplina em sala de aula. No que tange aos processos avaliativos, a relação com os professores e mesmo a convivência com os demais alunos da escola, os educandos relataram terem bons relacionamentos com seus professores, serem tratados com respeito na escola, além de afirmarem o desejo por aprender e o entendimento da necessidade de concluir seus estudos.

A pesquisa, portanto, também demonstrou que o alunado da EJA é plenamente capaz de perceber e julgar o processo educativo ao qual são submetidos. São pessoas plenamente capazes de aprender e até mesmo de ensinar, mas que por suas condições sociais e econômicas vivem às margens da sociedade.

Lembrando Paulo Freire (1996, p. 74-5),

Se a marginalidade não é opção, o homem marginalizado tem sido excluído do sistema social e é mantido fora dele, quer dizer, é objeto de violência. O homem marginalizado não é "um ser fora de". É, ao contrário, um "ser no interior de", em uma estrutura social em relação de dependência para com os que chamamos falsamente de seres autônomos. [...] Na realidade, estes homens analfabetos ou não - não são marginalizados. Repetimos: não estão "fora de", são seres "para o outro". Logo, a solução de seu problema não é converterem-se em "seres no interior de", mas em homens que se libertam, porque não são homens à margem da estrutura, mas homens oprimidos no interior desta mesma estrutura que é responsável por esta mesma dependência. Não há outro caminho para a humanização - a sua própria e a dos outros -, a não ser uma autêntica transformação da estrutura desumanizante.

Esses alunos da EJA têm sido colocados à margem da sociedade, pois o analfabetismo, por si só, já é um estigma capaz de segregar socialmente, e na contemporaneidade isso é nítido, especialmente frente ao aumento constante das exigências para conseguir um emprego, razão pela qual muitos procuram concluir seus estudos. Arroyo, (2005, p. 33) salienta que

Há constâncias que merecem a atenção das pesquisas e das políticas públicas: por décadas esses jovens e adultos são os mesmos, pobres, oprimidos, excluídos, vulneráveis, negros, das periferias e dos campos. Os coletivos sociais e culturais a que pertencem são os mesmos. Essas constâncias históricas têm sido mais determinantes na história da sua educação do que a indefinição, imprevisão e diversidade de atores, de ações, espaços e intervenções 
Isto tudo torna urgente a necessidade de uma reformulação do sistema educacional brasileiro, que torne o educando, especialmente o aluno da EJA, sujeito atuante de seu próprio processo de ensino aprendizagem, mas para que isso venha a se concretizar como uma realidade, são necessários uma reforma educacional e uma reformulação dos cursos de formação de professores capacitando-os a atuar frente a essa realidade, sendo mais urgente ainda a criação de formações específicas voltadas para atuar diretamente na EJA.

\section{CONSIDERAÇÕES FINAIS}

A existência da modalidade EJA é reflexo da demanda, indicando que ao longo de sua história educacional o Brasil não foi capaz de manter todas as crianças na escola, propiciar condições que impedissem a evasão escolar, e tão pouco de levar a educação a todos os cantos e recantos do território, existindo pessoas que não puderam estudar simplesmente por não haver uma escola a qual pudessem frequentar.

O estudo constatou que o aluno da EJA quer aprender, pois precisa de uma formação que o capacite a encontrar um emprego melhor, mas primordialmente ele também quer aprender. Portanto, os adultos e jovens precisam ser tratados com mais respeito pelos governos, para que sua dignidade seja respeitada, e o direito à educação possa ser de fato efetivado em nosso país.

Demonstrou-se que os professores, em sua maioria, desejam fazer um bom trabalho, respeitam o aluno e buscam entender sua realidade, trabalhando em consonância com ela. Não obstante, o próprio sistema organizacional da educação em EJA coloca entraves na qualidade do trabalho docente. Ficou claro que a EJA ainda precisa passar por várias mudanças para poder mudar a vida de muitos brasileiros, para gerar e dar várias oportunidades para que esses sujeitos possam crescer, primeiro como cidadão, primeiro intelectualmente, e, consequentemente, em suas carreiras profissionais, alimentando a máquina do Estado.

O objetivo geral deste artigo foi demonstrar, no âmbito da EJA, os resultados das entrevistas realizadas diretamente com os atores sociais do município de Vila Velha, analisando suas perspectivas. Considera-se que tal objetivo foi cumprido, e, para além dessa demonstração proposta inicialmente, foi também possível perceber que a mentalidade dualista de educação se mostra bastante vigente no escopo da EJA.

Além disso, há uma mudança na perspectiva dos processos avaliativos, embora ainda haja professores que entendem provas e notas dentro dos moldes da pedagogia do exame. Ademais, constatou-se que os professores valorizam profundamente sua relação 
com os estudantes, e entendem que o processo de aprendizagem está atrelado à confiança e à estabilidade emocional com que pode envolver o aluno. Sentem-se exemplos.

São exemplos. Dentre as dificuldades apontadas, sobressaiu a questão do multisseriamento e os transtornos causados pela inexistência de uma separação mais bem cuidada entre os alunos, o que poderia proporcionar tanto a melhoria na atenção que o professor dedicaria ao aluno, quanto ao próprio desenvolvimento do estudante.

Finalmente, ressalta-se que o enfoque dado no presente trabalho prezou pela busca da emancipação histórica dos sujeitos através do processo educativo, pensando na formação da inteligência, mas também do caráter, da cidadania, não apenas como uma máquina que atenda às exigências da economia capitalista vigente e em expansão.

Nesse sentido, concluiu-se, como ponto mais relevante das informações coletadas, a perspectiva adotada pela grande maioria dos professores da EJA, da importância dos alunos da EJA estarem preparados profissionalmente, preparados para o mercado de trabalho. Essa é uma postura que coaduna completamente com a consolidação do pensamento elitista e dualista. Não se está afirmando que os alunos não devam estar preparados para o mercado profissional, mas, no âmbito da Pedagogia Libertadora, a formação profissional não é o fim. A finalidade maior da educação é a construção do sujeito crítico e capaz em sua plenitude cognitiva, emocional, cultural e social.

\section{REFERÊNCIAS}

ALMEIDA, A; CORSO, M. A. A Educação de Jovens e Adultos: aspectos históricos e sociais. In: Educere - XII Congresso Nacional de Educação, Paraná, PUCPR, out. 2015.

ARROYO, M. G. Educação de jovens-adultos: um campo de direitos e de responsabilidade pública. In: SOARES, Leôncio; GIOVANETTI, Maria A.; GOMES, Nilma L. Diálogos na educação de jovens e adultos. Belo Horizonte/MG: Autêntica, 2005.

BESERRA, V. BARRETO, M. O. Trajetória da educação de jovens e adultos: histórico no Brasil, perspectivas atuais e conscientização na alfabetização de jovens e adultos. In: Cairu em Revista, ano 3, n. 4, p. 164-190, jul/ago. 2014.

BRASIL. Secretaria de Educação Continuada, Alfabetização e Diversidade. Coleção Cadernos de EJA. Brasília: MEC, 2006.

COOK-GUMPERZ, J. A construção social da alfabetização. Porto Alegre: Artes Médicas, 1991.

FREIRE, P. Pedagogia da Autonomia. São Paulo: Paz e Terra, 1996. 
FREIRE, P. Pedagogia do Oprimido. 47. ed. Rio de Janeiro: Paz e Terra, 2008.

FREITAS, L. C. Ciclos, seriação e avaliação. São Paulo: Editora Moderna, 2003.

FREITAS, W. R. S.; JABBOUR, C. J. C. Utilizando estudo de caso(s) como estratégia de pesquisa qualitativa: boas práticas e sugestões. In ESTUDO \& DEBATE, v. 18, n. 2, Lajeado, p. 07-22, 2011.

GADOTTI, M.; ROMÃO, J. E. (org.). Educação de jovens e adultos: Teoria, prática e proposta. 12 ed. São Paulo: Cortez: Instituto Paulo Freire, 2011.

LAFFIN, M. H. L. F. Educação de jovens e adultos e educação na diversidade. Livro 1. Florianópolis: NUP - Núcleo de Publicações do CED, 2011.

LUCKESI, C. Avaliação da aprendizagem escolar. 12 ed. São Paulo: Editora Cortez, 2002.

PELLOSO, S. M. Reflexões sobre avaliação: esboçando retrato da EJA. In: Os desafios da escola pública paranaense na perspectiva do professor PDE. v. 1, Curitiba: Governo do Estado do Paraná, 2014.

PORCARO, R. C. Os desafios enfrentados pelo educador de jovens e adultos no desenvolvimento de seu trabalho docente. In: EccoS Revista Científica, n. 25, p. 39-57, jan./jun., 2011.

SAVIANI, D. História das ideias pedagógicas no Brasil. 2 ed. Campinas, São Paulo: Autores Associados, 2008.

TEIXEIRA, A. Educação não é privilégio. 5 ed. Rio de Janeiro: Editora UFRJ, 1994.

VILA VELHA. EJA - Educação de Jovens e Adultos. Vila Velha: Prefeitura Municipal de Vila Velha, 2013. 